\title{
Plus ça change? Continuity and change in UK legislative drafting practice
}

by Stephen Laws

The Sir William Dale Lecture for 2008 was given on November 3 by Stephen Laws $\mathrm{CB}$, First Parliamentary Counsel, Office of the Parliamentary Counsel.

\section{INTRODUCTION}

Writing in 1927 the eminent American jurist and future Supreme Court justice Professor Felix Frankfurter said in his monograph on "Mr Justice Holmes and the Constitution":

"The eternal struggle in the law between constancy and change is largely a struggle between history and reason, between past reason and present needs."

The title for this lecture was suggested at least partly by the realisation that this struggle - which I shall describe in more conventional terms as a struggle between "continuity" and change - is one that I recognise as a recurrent theme throughout my working life. Though, I suspect it may have been a struggle for the Parliamentary Counsel since their inception in 1869 .

What I seek to do in this lecture is to illuminate current UK drafting practice in the light of that struggle over the past 35 years. The tension I wish to address, however, is different from the one that is of such importance to an American constitutional jurist considering the tension between constancy in the law by adherence to the wording and the decided cases on the meaning of the Constitution and the "change" that results from adapting it to fit modern conditions.

On the other hand, the potential for a comparable developing tension in the principles of UK statutory interpretation in the context of the Human Rights Act 1998, and the increasing importance of a developing doctrine of the separation of powers, is something I shall briefly touch on, and one of the reasons I thought it apt to start with the US quotation.

For a legislative drafter, the contrast between anything at all and change is one that has to be discussed in a context in which it is change itself that is the constant. The paradox of Heraclitus of Ephesus, "there is nothing permanent except change" certainly applies to the legislative drafter. The principal — and arguably the only — function of the drafter is to change the law. One of the guiding doctrines of UK Parliamentary Counsel has always been that unnecessary material in statutes tends to turn septic. UK drafters have traditionally sought to avoid the inclusion of anything in legislation that goes beyond a legal change, or which distracts from the change that is required.

On that basis, the struggle for the drafter is to reconcile the demands of continuity with an imperative for change. The complication is that, as I see it, demands for continuity have been operating within a context which is itself constantly changing: partly as a result of other legislation, but also as a result of outside factors, legal, social, political, environmental and so on.

My question is what sort of change, or at least adaptation, do the legal, social and other changes going on in the context require to the way legal change itself is effected and expressed, by drafting? How are those requirements reconciled with often equally compelling demands for continuity? Are there respects in which remaining constant to a traditional method might itself deny the effectiveness of a change legislation seeks to produce?

\section{CONTINUITY}

It is in some respects a primary function of law to preserve continuity. The author of my opening quotation, Mr Justice Felix Frankfurter, during his subsequent judicial career, addressed in Helvering $v$ Halloch 309 US 119 (1940) the tension between constancy and change in the interpretation of the US constitution in these words:

"We recognise that stare decisis represents an important element of social policy. It represents an element of continuity in law and is rooted in the psychologic need to satisfy reasonable expectations."

An important element of the case for continuity in the way legislation is drafted is the need for the form of law to satisfy reasonable expectations. Many eminent jurists, including Lord Bingham in the Sixth Sir David Williams 
lecture on "The Rule of Law" have emphasised the importance of continuity and predictability as a component of the rule of law. An element of predictability and permanence is an essential contributor to the role of law in preserving social cohesion and doing justice.

The same applies, I suggest, to how it is expressed. An understanding of the principled bias of the law in favour of continuity is essential to the drafter of legislation, who is better being predictable than indulging a talent for surprise. As Ben Johnson said in Timber or Discoveries made upon Men and Matter (published posthumously in 1640): "A man coynes not a new word without some peril and lesse fruit, for if it happen to be received, the praise is but moderate; and if refused, the scorne is assured."

But I suggest that the demands of continuity are not constant. For at least 35 years the relationship between what the transatlantic lawyer would call the three branches of government has been changing. The dynamism in the relationship has been attributable in part to some major legislative and constitutional changes, but it has also been influenced by other factors. It is that dynamism in the relationship that sets the context for legislative drafting that has proved both a challenge and a fascination to those of us who have had to work within it. Not only has the drafter often been aiming at a moving target. The drafter has also often been aiming from a moving platform. What I want to discuss is how much our practices have changed to match the changing context.

In my chapter for the book Drafting Legislation - a Modern Approach (The collection of essays in memory of Sir William Dale, which I understand is to be launched after this lecture), I explain how the role of the drafter is that of "drawing the line" and about how that contrasts with the work of the ordinary practising lawyer whose job is to "find the line". I explain how, in drawing the line, the drafter has to make a whole series of balancing judgments that set the parameters for what amounts to good drafting. That chapter is about the freedom of the individual drafter when confronted with a blank piece of paper, but it is also about the constraints that affect how the individual drafter resolves various tensions in the case of an individual piece of work.

In discussing continuity and change in drafting practice, and thus in the collective approach to drafting within our jurisdiction, I am today dealing with a further factor acting as a constraint on the drafter. That extra factor is the need to be consistent with what has to be a collective understanding of the developing and changing relationship between the courts on the one hand and Parliament and the executive on the other. That context sets the syntax for drafting and, collectively, drafters need to adapt to the changing syntax, while remaining conscious that the adaptation can itself either effect or inhibit further change, and that they need to assess that and be cautious about it.
The extent to which a collective approach is needed is of particular interest to me in my current capacity as the leader of an office of legislative drafters. The head of every drafting office has to make judgments on what is appropriate where there are competing claims for consistency and innovation.

So, what — for drafters of legislation collectively — is the importance of continuity?

The essential prerequisite for being able to draft effective legislation is to be able accurately to predict how it will be applied in practice. That means working with the grain of the interpretative principles currently applied by the courts and it involves safeguarding principles and practices that maintain order and consistency in the whole process.

The demands of continuity require a balance to be struck about how new propositions are approached. This involves looking at the demands of continuity by looking both forwards and backwards. Looking forwards, it is important for what is drafted to be understood both immediately and in the longer term. This applies not only to the Bill, and the resulting Act, but also to future Bills and Acts to be drafted either by the drafter or by his or her colleagues.

Immediate comprehensibility in Parliament is essential if the Bill is to pass. Immediate effectiveness on commencement is also essential to deliver the implementation of the government policy to which an Act is to give effect. Those factors draw the drafter into the specific and the contemporary. They present an incentive to accede to requests for immediate clarification or exposition in the legislation.

However, the drafter must also look further into the future. There are risks in concentrating solely on the immediate implementation of the Act. The potential lifetime of statute law imposes an imperative for continuity in the style and general approach to drafting. Much statute law may appear to the practitioner to be a transitory thing renewed and altered with regularity. But statute law needs to be drafted in the knowledge that it must make sense not only today, but also next year or in 10 or even, like the US Constitution, in over 200 years time.

Here is a factor that draws the drafter into the abstract and a use of language that is conservative enough to stand a chance of passing for timeless. Of course Alexander Pope's advice (in An essay in criticism, (1711), at p 333), also plays a part.

$$
\begin{aligned}
& \text { In words, as fashions, the same rule will hold; } \\
& \text { Alike fantastic, if too new, or old: } \\
& \text { Be not the first by whom the new are tryed, } \\
& \text { Nor yet the last to lay the old aside. }
\end{aligned}
$$

Looking forward in a strategic way, the drafter must not debase the coinage of communication for the future. Every Bill (even if it is not making major constitutional or legal 
change) is potentially contributing to expectations about the form and content of future legislation. A clarification that short-term considerations might make desirable can be undesirable if it will create an implication that the matter will always be clarified in future. The expression of an idea in a novel way may create an assumption that the idea will continue to be expressed in that way. Drafters need to remember that divergent practices, when examined close up, can be analysed chronologically and made to look like a collective change of direction.

On the other hand, this analysis prompts me to wonder whether one thing drafters have to recognise is the extent to which a period of very significant change in the context in which legislation is interpreted itself creates a tendency to greater volume. In such a period, the long-term statutory outcomes are likely to be less predictable because they depend on the direction of future change. If, as a result, the balance, for both the drafter and others involved in the framing of legislation, between achieving short-term effectiveness and securing long term stability shifts in favour of the the short term, what effect will that have on the character of the legislative product? And how should the drafter manage that potential effect?

Continuity is also reinforced when the drafter looks backwards. At that point, similar considerations apply as when looking forwards, although sometimes the backwards look leads to different conclusions.

First, looking backwards at the immediate past, it is important that the new law fits with the old. The common characteristic of every legislative provision is that it is changing law, not just making new law. Has the connection with the previous law and the transition from it been adequately provided for? Just as there must be no holes in the new law, so there must be no holes in the old law where the join is made with the new. This is one area where continuity must clearly be an element of change. I discuss in my Chapter for Drafting Legislation - a Modern Approach how the drafter may have to decide whether to put the emphasis in a draft on the destination of the proposed legal change or on the route to that destination. But continuity demands that there should always be a route.

Secondly, looking backwards, the drafter must ensure that the drafting approach does not prejudice the interpretation of provisions that have already been drafted. Here is a real tension between continuity and change. Just as an innovation in drafting may commit future drafters to a particular approach for the future, it can also condemn them for not having adopted a particular approach in the past. A change of approach may be wholly justified by new circumstances, but it may still carry a risk of creating a misleading impression about the drafting of past Acts.

This can be complicated if the common law background is itself developing to undermine the premise on which previous legislation was written. (An example would be the development of a remedy for the recovery of money paid under a mistake of law - see Beatson, J, (2006) "Common law, statute law and constitutional law” 27 SLR 1). Must the drafter accept and ratify a development and so, perhaps, accelerate the mismatch with previous legislation - particularly if a retrospective cure for the earlier legislation is likely to be impossible? Or should the drafter risk being left behind by a development that has begun but the future shape of which remains unclear?

Drafters worry about the risk of unintended consequences outside their range of vision. It is understanding this area of uncertainty that gives importance to continuity and imbues the drafter with caution about the risk of inadvertently demolishing a load-bearing wall

So, the claims of continuity are great. They lead to the principle that legislation must be drafted in the way in which the courts expect to be communicated with. There must be a sound analysis of principles and ideas, and the legislation must confine itself to communicating exactly what it is necessary to communicate.

\section{CHANGE}

What happens, though, if the expectations of the courts change, whether as a result of changes of practice or law or because of other factors beyond the control of the legislature or the drafters? When is it sensible and when is it constitutionally appropriate to allow changes of expectations to affect the process of legislation? To what extent is it possible for the courts to change legislative drafting practice by changing expectations? And are such changes, like other common law changes, to be regarded as involving statements of what the law has always been and therefore retrospective. Do they not place the drafter in the dilemma I have just described, where more substantive background law is in the process of development?

There are certainly some changes of expectation drafters cannot ignore and those are the ones they themselves are responsible for. As I have said, the drafter is not working within a fixed system. Change is what we have to do; and too much caution about change may equally result in ineffective legislation. Every piece of the drafter's own work has the potential to change the system itself, both the system within which legislation is made and the system within which it will be construed. And those changes at least have the authority of the Queen in Parliament.

The period of 35 years of change, at which I wish to look, is not chosen at random and contains changes that raise all these questions. It is just over 35 years since I was called to the Bar. The period covers my entire professional life — so far. Furthermore, using 1973 as a starting place enables me to include what everyone will accept was a major transforming change to UK law, namely, the accession of the UK to the European Communities and the commencement of the European Communities Act 1972 (ECA). Finally, by choosing this period, I can use, as a benchmark, two reviews of the state of legislative drafting 
in the UK that took place near the beginning of the period: the Renton Committee report in 1975 on The Preparation of Legislation (Cmnd 6053) and the 1977 book Legislative Drafting: A New Approach (Butterworths) by the late Sir William Dale, in whose honour this lecture series is named.

It is difficult to find the right order in which to discuss the different changes that have occurred. The impact of each has emerged gradually over time. So there is a considerable area of uncertainty about the extent to which they have operated together, or have impacted on each other.

Even the incorporation of EEC/EU law into UK law, which can be precisely timed, did not have an immediate impact. My own memories of joining the public service in 1975, and the Office of the Parliamentary Counsel in 1976, are that initially the likely impact of EEC law was expected to be of relatively limited significance for the UK legislator. EC laws were thought to concern a narrow range of matters dealt with by UK law; and the constitutional impact of section 2 of the ECA 1972 was not at first fully accepted in practice.

Drafters worried more about the risks of inadvertently repealing the effect of section 2 by providing for something inconsistent with European obligations, than about producing something that was ineffective or obscure because of an inconsistency with a European law with superior authority. The position did not really begin to become clear until 1981 and the case of Macarthys Ltd $v$ Smith 129/79 [1981] QB 180. Even then I would suggest it took until Factortame in 1991 ( $R_{v}$ Secretary of State for Transport, ex p Factortame Ltd (No 3): c-221/89 [1992] QB 680) fully to sink into UK legal consciousness. It is interesting that the process of accepting a form of quasientrenchment has been much quicker with the Human Rights Act 1998, perhaps because of the previous EEC experience.

A better starting place for a discussion of the impact on legislative drafting of change over the past 35 years is the analysis of legislative practice that appears in the Renton and Dale reviews. In Chapter VI of the Renton report the criticism was set out as follows:

"6.2 The complaints we have heard may be broadly grouped as follows:

(a) Language. It is said that the language used is obscure and complex, its meaning elusive and its effect uncertain.

(b) Over-elaboration. It is said that the desire for "certainty" in the application of legislation leads to overelaboration.

(c) Structure. The internal structure of, and sequence of clauses within, individual statutes is considered to be often illogical and unhelpful to the reader. (d) Arrangement and amendment. The chronological arrangement of the statutes and the lack of clear connection between various Acts bearing on related subjects are said to cause confusion and make it difficult to ascertain the current state of the law on any given matter. This confusion is increased by the practice of amending an existing Act, not by altering its text (and reprinting it as a new Act) but by passing a new Act which the reader has to apply to the existing Act and work out the meaning for himself."

Dale diagnosed the problem as unintelligibility resulting from obscurity and excessive length. He said:

"Features making for obscurity or length, usually both, in United Kingdom Acts are -

(a) long, involved sentences and sections;

(b) much detail, little principle;

(c) an indirect approach to the subject-matter;

(d) subtraction - as in "Subject to", "Provided that";

(e) centrifugence - a flight from the centre to definition and interpretation clauses ("the famous freak of modern law givers");

(f) poor arrangement;

(g) schedules - too many and too long;

(h) cross-reference to other Acts - saving space, but increasing the vexation."

Have there been changes in drafting practice that suggest a response to those criticisms? Certainly, there are examples of the same criticisms being repeated today. But is that justified? The criticism of the statute book tends to come from those who read Acts of many different dates, rather than from those who confine themselves to reading current Bills. It takes time for a change to have an impact on the whole corpus of statute law.

My observation is that there have been some very considerable changes in the use of language and in the structuring and detail of legislation and in the use of cross references. I am not claiming that everything has always moved in the same direction. But I do assert that a comparison of today's Acts with those of 30 years ago will reveal a general simplifying trend and the modification of techniques with a view to enhancing both clarity and readability. Has this been the result of the criticisms voiced at the beginning of my period? Or have other factors been influential?

As one of the few current members of the Office who was drafting in the 1970s, I doubt whether that consensus of criticism in the Renton Report and Dale's book was entirely fair at the time. I believe that a comparison at that time between Acts of Parliament and other legal documents on the basis of the Renton and Dale criticisms would have come down in favour of the Acts. Nevertheless, 
I think it would be fair to say that the consensus of the criticism is one of the factors that has contributed to change, as has the movement for the simplification of the drafting of other legal documents. On the other hand, there are certainly other factors too that have contributed to the attachment of even greater importance to accessibility and readability.

We do need to recognise however that the case for simplicity in legislation and plain language is not new. One of my favourite provisions in this context is from the Act for the establishment of the succession of the Crown of this realm of 1536, which provides that the provisions of the Act shall:

"be taken and accepted according to the plain words and sentences therein contained, and shall not to be interpreted or expounded by colour of any pretence or cause or by any subtle arguments, inventions or reasons to the hindrance, disturbance or derogation of this Act"

This, it has to be remembered, is the Act that declared the marriage to the King of Anne Boleyn — attainted for treason on account of her adultery — to be void ab initio.

Returning however to the last 35 years, an example of a change of practice that was attributable both to outside criticism and to other factors is the expansion of the use of textual amendment as a technique for changing the law. The move to textual amendment had already begun some years before I joined the Office of the Parliamentary Counsel in 1976, but it was ratified and reinforced in chapter 13 of the Renton report. Other factors, however, were also influential.

The theory that each Act was an independent proposition changing the law and so needing, so far as possible, to be self-contained in order to satisfy the requirements of Parliament had been questioned as a result of the extra push for consolidations that followed the establishment of the Law Commissions in the 1960s (see for example, Chorley and Dworking, "The Law Commissions Acts, 1965" 28 MLR 675 at 681). At the same time too there was a developing expectation that publishing techniques, the Statutes in Force project (Statutes in Force: official revised edition, London, HMSO, last edition 1996) and so on, would facilitate the accessibility of "as amended" texts, the previous absence of which had made textual amendment sometimes unattractive. Then, since the 1970s rapid technological advance has reinforced the availability of "as amended" texts and so embedded textual amendment further into UK drafting practice.

On the other hand, there has not been a shift to the system often found in Antipodean jurisdictions, where large Acts on particular topics are treated as conceptual loose leaf binders into which all subsequent changes have to be fitted. In some areas there is a tendency in this direction in the UK, but in others we are still very far from that approach.
Tax law and social security law have been re-enacted, each in a series of Acts passed to cover the whole story, and most changes are fitted textually into the text of those Acts. Education law, on the other hand, tends to accumulate in many different successive Acts. I have no certain or clear explanation for this.

One factor may well be the way the tension between continuity and change manifests itself in English law, and maybe also in the UK Parliament, in a reluctance to accept the notion of a statutory code. This means that, in the UK - perhaps more than elsewhere, legislation and the process of legislating is seen as an interference with the existing corpus of law, a set of running repairs on an existing structure.

We are reluctant to start again, often perhaps because it can be difficult to get a very clear picture of how we got to where we are. The fear of inadvertently demolishing a loadbearing wall raises its head again and the claims of continuity prevail over the desire to produce a clean reenactment. Furthermore the other demand of continuity: the need to understand not only where we are, but also the route we have taken to get there - is also an incentive to draft in a way that tells a chronological story rather than presents the reader with a series of tableaux in freezeframe.

I mentioned new technology and how it has reinforced the practice of textual amendment. New technology has also had a wider impact on the way legislation is written, as well on the way it is interpreted. I have been heard to say that when I entered Office of the Parliamentary Counsel in 1976, new technology consisted of a plastic eraser and a propelling pencil.

Today every drafter works with a keyboard and software that takes much of the routine load off the individual. It is no longer the task of the drafter, every time a Bill is redrafted, manually to re-number all the clauses and subsections that have been affected by insertions and deletions and then manually to correct all the internal cross-references. This can be, and is, done mechanically. Verbal consistency no longer requires a complete readthrough. The search facility has transformed the task of producing an internally consistent document.

It would be foolish to ignore the effect this change has had both on the process of legislation and on the product. More generally too, the impact on ideas of the practical technicalities by which they can be recorded and communicated is a fascinating subject.

My observation is that one major transformation produced by new technology has been to reduce the risks of revision. A 1970 s drafter was probably much more reluctant to undertake a radical revision of the text, because of a much higher risk of inadvertently losing some important element.

Giving the drafter a computer on which the text can be instantaneously reworked is a world away, or at least now 
almost a working lifetime away, from that in which a shorthand typist had to be summoned to effect the change with as many carbon copies as were needed, and where the result had to await the drafter's turn in the queue for typing services.

There may be neophobes who will say that new technology has undermined the disciplines that kept legislation concise and clear. And there is a case to be made for that. Some disciplines that operated to develop a habit of accuracy and conciseness and were inculcated by the mechanics of doing the job now have to be taught more directly and consciously allocated a suitable priority.

However, I do not lament that. Partly that is because there is no point in doing so. The changes were inevitable. But it is also because the benefits, in my view, outweigh the losses, so long as the losses are identified and a proper assessment made of what is needed to mitigate them. The world where revision is less of a risk is the world where the drafter has more opportunities to perfect the legislative text.

In some areas of the law computers may be thought to have led to prolixity and a loss of original thought. I do not believe that to be true of legislative drafting. The efficiency produced by new technology has produced a much greater facility for revising text. Even if the majority of the extra time produced by the efficiency is used on other priorities, some of it at least is now usable on producing greater simplicity and readability. Today, we may have the risk created by the opportunity to make a last minute change - of producing a last minute error. My view is that we cannot regret that there was probably a higher risk of error when old technology denied us the use of the last minute.

New technology has increased the efficiency of drafters, both when drafting and when doing research. It has also correspondingly changed the way legislation is read much is now read in chunks online - and it has also increased the facilities for research by those who seek to construe it. That, I believe, has been another significant aspect of the change over the last 35 years to the context in which legislation is read. There is too some evidence for a developing consequential change in the way it is being written.

The decision in Pepper v Hart [1993] AC 593 gives rise to different emotions amongst those concerned with legislation. For me though it represents a symptom of a change of much wider impact and an important factor to be considered when looking at the dynamism of the relationship between the courts and legislators.

For as long as I have been in the law, a tension has been said to exist between those who assert a preference for literal interpretation and those who assert a more "purposive" approach. However, that tension still seemed relatively unreal when the rules about identifying the purpose effectively confined the material to which reference could be made to the text of the Act.
The drafters' reaction to Pepper $v$ Hart was generally phlegmatic. We were concerned that the decision created research difficulties - difficulties that have now been mitigated, but not removed, by new technology. Finding a ministerial statement on a provision was difficult. Difficulties included the way clause numbers can change at each Parliamentary stage, the way amendments are grouped for debate, often in a rearranged order, and the fact that what were then called standing committee proceedings (where most detailed debates on legislation took place) were published in limited editions that did not make them easily accessible.

But when asked about the impact of the substance of the decision on our work, we said that the words of the statute were our only tool: so provided that we got the provisions clear — so that, on a literal reading, they were unambiguous and did what was required by our instructions — then we had no need to worry.

The significance of Pepper v Hart, though, as I now see it, was that it was symptomatic of a more general trend, or perhaps it was the catalyst for the acceleration of that trend. The trend is for the courts and others increasingly to look outside the text of the Act for its meaning. This is a tendency that has been noticed and commented on by others before me (I would like to express my gratitude to Lord Rodger of Earlsferry for the help provided to me in developing my ideas for this lecture by his address to the Office of the Parliamentary Counsel in May this year).

The use of explanatory notes for Bills in Parliament as a way of providing clear explanations for Parliament of their effects had been championed by the Office of the Parliamentary Counsel. The notes could set out in plain language the whole context of a provision. And we championed them at least partly because they provided a vehicle to which we could, in the interests of continuity, divert all the unnecessary material that we should otherwise have been invited to include in the text.

Looking back, it is possible to question how successful that strategy has been. The use of explanatory notes to protect the purity of the legislative text is undermined if they become too readily a tool for construing the Act (see Dr Roderick Munday, "Explanatory notes and statutory interpretation", (2006) 170 Justice of the Peace 124-32); and, as others have shown, there is an increasing tendency to use them in that way.

In that context I detect some evidence that the increased willingness of courts to look beyond the text may be producing a relaxation - but not, I hasten to say, an abandonment - of the rules drafters apply to themselves about the inclusion of explanatory material in legislative text. There is still a rigid adherence to a rule that explanatory material must be clearly identifiable as such, but I observe that such material is no longer rigorously excised. 
The use of framework clauses and more signposts, particularly in the work of the Tax Law Rewrite Project, is indicative of the change. It represents a conscious change of direction from that project, but it is also an approach that has been carried into individual practice on other Bills. The new parameters may not yet be clear. But the cautious development of new boundaries provides a good illustration of how a whole range of changes and influences can result in a shift in the balance between continuity and change in the practice of legislative drafting. The demands of continuity remain. It is still dangerous to put unnecessary material in statutes. But in many cases the risk of doing so is being assessed in a slightly different way from the way it was in the past.

So this aspect of a recognisable move away from a fundamentally textual approach to a more teleological approach may be affecting the way drafting is done. Interestingly, the move in the courts coincides with a similar change in the way legislative proposals are debated in Parliament. There is less debate now on the literal effect of the Bill. This change has been encouraged by Parliamentary changes under which the programming (viz time-tabling) of debate on a Bill in the Commons has become the usual practice. Programming has spread the debate on a Bill more evenly and encouraged a greater concentration of debate on points of principle and purpose, rather than textual analysis. Previously, Parliamentary debates on a Bill would often include a substantial period devoted to a relatively random sample of points on the technical or textual detail.

The procedural changes have also meant that there is less incentive for the drafter to produce the shortest possible text in the smallest number of clauses. That increases volume but it also contributes to readability and simplicity, enabling provisions to be split and broken down into shorter, clearer propositions, rather than rolled together to save space.

I want to emphasise that in describing the procedural changes I am making no criticism. The duty of Parliament is to debate legislation in whatever way Parliament thinks best serves those whom Parliament represents.

My observation, though, is that a concentration on purpose and principles both in the courts and in Parliament means that more and more extraneous material is being accessed to find out what the words we have drafted mean. I detect too that, in practice, there is an increased willingness for readers of Bills and of Acts to turn to extraneous material, not only if the literal text fails to yield a certain meaning, but rather to reinforce - before the text has been wholly exhausted as a source of meaning - what was in fact only a preliminary assessment of its intention.

This gradual but general loosening of the connection between the legal meaning of a piece of legislation and the detail of its text has been reinforced by other factors. One of these I have already mentioned: the incorporation of EU law into UK law. There can be no denying the impact of EU law on the way UK law has developed over the past 35 years. Several different factors have contributed to that.

Sir William Dale in Legislative Drafting: A New Approach drew attention to what he claimed to be a different approach to legislation in continental jurisdictions: "The continental law makers, influenced by their heritage of codes, think out their laws in terms of principle, or at least of broad intention, and express the principle or intention in their legislation."

The approach in EU legislation is certainly different from that in a traditional UK statute, but I am not sure that this distinction, founded on the supposed and traditional distinction between continental rationalism and English empiricism, sums it up. In my English, empirical way, I would prefer to list factors that I think mean that EU provisions differ in approach from the traditional UK approach.

First, both the text and the policy of EU law is negotiated in a way that UK statutes are not. A UK statute takes a form which gives effect to the policy of the UK Government. These days policy is seldom formulated without extensive consultation, and Bills have to be acceptable to Parliament; but the legislation ultimately always gives effect to decisions by the executive that others are invited to accept. A negotiated document is different, because different views about its meaning may continue after promulgation amongst all those who contributed to its formulation.

Secondly, EU legislation is designed to fit several jurisdictions and is not tied to place in the same way as UK legislation.

Thirdly, as Dale suggests, it is not tied to particular ways of legal thinking. It is true that some continental systems think from principles to rules, whereas the tradition of English law has always been to infer rules and principles from particular outcomes. This has an effect on the way it is drafted; but it would be wrong too to suggest that EU legislation has not also been influenced since 1973 by the common law approach of the UK and the Republic of Ireland.

Finally, EU legislation is drafted in, and to fit, several languages, and this involves an element of uncertainty about its application.

The development of the principles of direct applicability, a desire, in the interests of minimising unnecessary regulation, not to gold plate the implementation of EU obligations and indeed the decisions of the courts have all led those implementing EU legislation in the UK to rely more heavily on the technique of "copy out" - the transliteration, rather than the translation of EU law into UK law (see Rhone-Poulenc Rorer International Holdings Inc and another $v$ Yeda Research and Development Co Ltd [2006] EWCA Civ 1094 per Lord Justice Jacob, para 22). The 
consequence is that provisions in EU form can very often find themselves as neighbours to more traditional UK provisions. Inevitably the proximity has had an effect on what seems possible in the UK provision and doubtless too on the way it may be construed.

The extent to which EU law has influenced UK law is unclear because many of the differences to which EU law has introduced UK law have been mirrored in domestic developments. So the growth of pre-legislative scrutiny and consultation, and a corresponding expansion of the degree of involvement in legislation by those outside Parliament, has perhaps shifted the nature of legislation away from something that was exclusively the expression of will of the government towards something to meet the needs of different groups.

If it is still the case that the text of a UK statute is not a negotiated text, it is nevertheless the case that the policy it implements is more often negotiated. Certainly, there are today many more mechanisms for ensuring that policy involves a careful balance between the competing legislative ambitions of all those interested, including the executive.

Legislative and administrative devolution too has introduced more diversity of place and jurisdiction, and in Wales bilingualism, into UK law, with now three separate drafting offices, in addition to the Office of the Parliamentary Counsel in London, developing their own at least slightly different approaches properly attuned to local judicial, political and legislative conventions. It is clear that this diversity itself, coupled with the complexity of transition from jurisdiction to jurisdiction within the UK, places additional tensions on the ability to maintain a single and clearly identifiable textual approach — tensions, I should say, that all the drafting offices are working closely together to mitigate.

The need for legislation in all UK jurisdictions, including by convention in the UK Parliament, to respect the parameters of the different devolution settlements has also necessarily involved a more principle based-approach to legislation. The "pith and substance" test (see eg s 29(3) of the Scotland Act 1998 or s 94(7) of the Government of Wales Ac 2006) and the other similarly broadly framed tests of whether something is within devolved competence have thus become very powerful influences on the whole nature of UK legislation.

Yet another change that has had a significant effect over the past 35 years has been an acceleration in the development of administrative law and the principles of judicial review over that period. The start of the process had begun some years before the beginning of my period, but the extent to which the courts now consider it necessary and appropriate to question and review administrative decisions has expanded enormously over the past 35 years.

The development of the remedy and concept of judicial review, something that did not exist at all at the beginning of the period — although the prerogative writs did — may well have contributed to this, coinciding as it does with a changing relationship in a dynamic unwritten constitution, between the Executive and the courts.

The professionalisation of both the law and politics and related social changes have reinforced this so that the interpretation of statutes is now more of an arm's length affair. The establishment of the Supreme Court will remove the most senior judges from Parliament completely, and the proportion of members of the judiciary with experience as Parliamentarians is probably as low today as it has ever been.

These changes are associated too with the increased importance that is attached to a developing constitutional principle in favour of a genuine separation of powers. This is attributable to European/ ECHR influences as well as to the constitutional analysis required by the process of devolution. In the context of a developing doctrine of qualified entrenchment for certain UK statutes, I was struck too, recently, to hear a judge of the Irish Supreme Court explain that it is the separation of powers that does the job for the Irish Constitution that is achieved in the UK by the doctrine of the sovereignty of Parliament.

The Human Rights Act 1998 fits squarely within this line of development that in different ways seeks to define the proper constitutional role of the courts. By introducing international obligations into domestic law, that Act has introduced — and made more acceptable — the legal reasoning that proceeds from principles to rules, rather than vice versa and so invites the courts to intervene, on the basis of principle, in the administrative decisions made by the Executive under detailed statutory powers.

If these factors have exemplified a move from detail and literalism to principle and purpose, one complaint that the drafter has always had to meet, and has to meet still, is the complaint of increasing volume. I have said something about this already in the context of the discussion of new technology and of the extent to which the pace of change may have shifted the balance in favour of shorter term priorities. But if volume is a fault, the changes I mention here are all contributory causes to a steady growth in volume.

- the increasing use of extraneous material

- the effect on the form of legislation of wider consultation and pre-legislative scrutiny

- the demands of EU and ECHR compatibility

- the demands and effects of devolution

- the development and growth of administrative law

- the distance between courts and Parliament and the increasing influence of a doctrine of a separation of powers 
- the factors which require an approach to law that requires the identification of principles in specific rules and the subordination of rules to the principles.

All of these have evinced a response from the drafter that requires more words. The possibility that increased volume is one of the responses to these factors leads me on to the Tax Law Rewrite Project as a final factor that has effected a change in drafting practice. The Project was established in the late 1990s mainly in response to criticism of the increasing volume and apparent complexity of tax legislation. It is now expecting to complete its work on rewriting both income tax and corporation tax law in 2010. In the process it has made a significant contribution to the way legislation is drafted. Members of the Office of the Parliamentary Counsel have circulated through the project regularly over the past 10-12 years and, in the process, have picked up new techniques in the production of clearer and better organised statutes.

The work of the project has exposed a generation of drafters to new techniques. In the event, the development of these techniques have established that actually conciseness, sometimes, has to be sacrificed to clarity to cure the problem created by otherwise unavoidable volume. It has been a project where the default position was for innovation and simplification, rather than constancy to traditional techniques. It has been influential on main-stream drafting. Its experience was of considerable assistance to us in our recent switch to gender neutral drafting.

\section{CONCLUSIONS}

My conclusions are these. I have shown that the demands of continuity have to be respected by legislative drafters in order to protect the system within which they operate and to guarantee effectiveness. However, the system itself is constantly changing and that involves, and indeed often requires, a willingness to adapt legislative drafting practices

The changes affecting the system may result from express demands for change. But there are other factors at play and they are generally more significant. The different factors operate on each other; and what is cause and what is effect are hard to pin down. The factors include legislation modifying constitutional arrangements but even small changes of practice have a potential effect. Other factors include social changes, political developments, changes to the procedure and priorities of Parliament and Parliamentarians and even technological change.

Parliamentary Counsel need to respond to these factors cautiously because of the demands of continuity and the risk of themselves producing unintended change; but the same demands mean that they do have to respond to change around them and to do so sensitively and, if the forces for change are strong, collectively. Remaining constant to an outdated view of the context in which they are operating can result in ineffective legislation. Continuity demands the drafter to maintain a delicate balance in the midst of change. To return to Heraclitus on change "No man steps in the same river twice. He is not the same man nor is it the same river." Each Bill requires a new assessment of the balance. But the drafter's guide has to be a common understanding, with other drafters, of the current state of the competing demands of both continuity and the forces of change.

On the practical level, the Tax Law Rewrite Project provides a good illustration of a response by drafters to the need to preserve continuity and to meet an imperative for change. It shows how drafters can respond collectively to secure continuity in the drafting of legislation, while allowing an innovative development of new techniques. The lesson is to find the common approach that best accommodates the forces of change - in that case the demand for more clarity and the need, as things turned out, to mitigate the consequences of increased volume, otherwise than by making things more compact.

I have identified a number of forces for change and have identified responses to those forces. Recent forces for change all have a common feature involving the attachment of increased relevance to factors that distract from the literal effect of the text. The appropriate response to change of that sort seems to me to be a collective acceptance by drafters of an even greater responsibility to ensure that the text of the legislation yields a clear answer.

So the responsibility of the drafter, when giving effect to the wishes of those instructing, becomes a responsibility to provide legislation that yields its meaning clearly and immediately in a way that cannot be falsified by anything (including external material or indeed extraneous analysis). But the text remains our only tool. Plus ça change.... The task is what it has always been: get the text right and make it the final answer. Maybe though, today's changed and changing context make that job just a bit more difficult.

\section{Stephen Laws, CB}

First Parliamentary Counsel, Parliamentary Counsel Office 